\title{
ABO Blood Groups in Covid-19 Patients; Cross-sectional study
}

\author{
Ihsan Solmaz ${ }^{1}$ and Songül Araç ${ }^{1}$ \\ ${ }^{1}$ Diyarbakir Gazi Yasargil Training and Research Hospital
}

October 23, 2020

\begin{abstract}
Aim: The aim of this study was to investigate the ABO and Rh blood group distribution and clinical characteristics in patients with Covid-19. Materials and Methods: The clinical characteristics and blood groups of 1667 patients who were hospitalized due to Covid-19 (with a positive PCR test) between 16 March and 10 July were reviewed cross-sectionally.. Results: When blood groups of patients diagnosed with Covid-19 and control group were compared, it was observed that there was increase in the number of Covid-19 patients with blood groups $\mathrm{A}$ and $\mathrm{AB}$, decrease in the number of Covid-19 patients with blood group $\mathrm{O}$, a statistically significant increase in the number of individuals with blood group A in Covid-19 patients compared to healthy individuals, and almost significant increase in the number of Covid-19 patients with blood group AB and a very significant decrease in the number of Covid-19 patients with blood group O. Conclusion: Our study has found that having blood group O may be protective, that blood group A may have greater susceptibility to the disease, but this does not affect the course of the disease and is not associated with mortality.
\end{abstract}

\section{ABO Blood Groups in Covid-19 Patients; Cross-sectional study} ABSTRACT

Aim : The aim of this study was to investigate the ABO and Rh blood group distribution and clinical characteristics in patients with Covid-19.

Materials and Methods: The clinical characteristics and blood groups of 1667 patients who were hospitalized due to Covid-19 (with a positive PCR test) between 16 March and 10 July were reviewed crosssectionally..

Results: When blood groups of patients diagnosed with Covid-19 and control group were compared, it was observed that there was increase in the number of Covid-19 patients with blood groups $\mathrm{A}$ and $\mathrm{AB}$, decrease in the number of Covid-19 patients with blood group $\mathrm{O}$, a statistically significant increase in the number of individuals with blood group A in Covid-19 patients compared to healthy individuals, and almost significant increase in the number of Covid-19 patients with blood group $\mathrm{AB}$ and a very significant decrease in the number of Covid-19 patients with blood group O.

Conclusion: Our study has found that having blood group O may be protective, that blood group A may have greater susceptibility to the disease, but this does not affect the course of the disease and is not associated with mortality.

\section{Summary statement}

What is already known about this topic?

There are some studies examining the relationship between Covid-19 and blood groups in the literature. It has been found that the rate of infection with SARS coronavirus is lower in blood group O.

What this paper adds? 
Our study showed that there was a very significant increase in the number of individuals with blood type A in Covid-19 patients compared to healthy individuals, almost a significant increase in the number of AB blood group Covid-19 patients with blood group $\mathrm{AB}$, and a very significant decrease in the number of Covid-19 patients with blood group $\mathrm{O}$

The implications of this paper:

Our study has found that having blood group O may be protective, that blood group A may have a greater susceptibility to the disease, but this does not affect the course of the disease and is not associated with mortality. We want to emphasize that the most important and easiest way to avoid Covid-19, regardless of the risk factor and the facilitating factor, is to maintain social distance, hand hygiene, and use of.

Keywords: Covid-19, ABO, Rh, Blood group

\section{Introduction}

The number of SARS-CoV-2 (Covid-19) cases, which was recognized as a pandemic by the World Health Organization (WHO) in March, continues to increase rapidly worldwide. ${ }^{1}$ As of July 2020, the number of Covid-19 patients reported by WHO has exceeded 13 million and the number of deaths 580 thousand. People most commonly affected by Covid-19 are those with chronic lung or cardiovascular diseases, men with hypertension and diabetes. ${ }^{2}$ There are some parameters such as CRP, ferritin and LDH that can predict the clinical severity of Covid-19, but there are no biomarkers indicating a predisposition to Covid-19. ${ }^{3}$

The general blood group system called ABO discovered by Landsteiner is a kind of cell identity system determined by the antigenic structure located on the erythrocyte surface. The Rh system, known as whether there is an antigenic structure or not, is another grouping. ${ }^{4}$ Blood groups are a qualitative characteristic in which there are no environmental effects, with all of the phenotypic variation being a reflection of the genetic structure. Blood group antigens are genetically encoded, and these antigens may be a predisposing factor for some diseases and a protective factor for some others. Studies have shown that some rheumatological diseases, viral infections such as Norwalk virus and Hepatitis B, and some types of cancer are associated with the ABO blood group. ${ }^{5-8}$ In addition, it has been found that the rate of infection with SARS coronavirus is lower in blood group $\mathrm{O}^{9}$

By examining the relationship of the human blood group with virus infection, it is possible to determine the susceptibility of people with different blood types to viruses. There are some studies examining the relationship between Covid-19 and blood groups in the literature. The aim of this study was to investigate the $\mathrm{ABO}$ and $\mathrm{Rh}$ blood group distribution and clinical characteristics in patients with Covid-19.

\section{Materials and Methods}

This study was conducted retrospectively between March 16 and July 10 in Diyarbakir Gazi Yasargil Training and Research Hospital with the data of patients who received inpatient treatment for Covid-19, obtained from the Hospital Information Management System. This study included 1667 patients who were admitted to the hospital, whose blood group information was registered in the system and who had a positive PCR test result, while patients whose blood group information was not registered in the system and those who had a negative PCR test result were excluded from the study. As the control group, data from the blood group study conducted with 127091 people in our province in 2019 were used. ${ }^{10}$

\section{Statistical Analysis}

Statistical evaluation was performed using SPSS 22 for Windows (IBM SPSS Inc., Armonk, NY, USA). Chisquare test was used for the comparison of categorical data. $\mathrm{p}<0.05$ was considered statistically significant.

\section{Ethical Approval}

Ethical approval was obtained from the local Ethics Committee. The study was conducted in accordance with the Declaration of Helsinki. 


\section{Results}

A, B, O, AB blood group distribution of individuals in our province was $39.7 \%, 18.6 \%, 33.6 \%$ and $8.1 \%$, respectively. Rh (+), Rh (-) blood group distribution was $88.4 \%$ and $11.6 \%$, respectively.

A, B, O, AB blood group distribution of 1667 patients, who were PCR-positive, was $45.17 \%, 18.65 \%, 26.81 \%$ and $9.35 \%$, respectively. $\mathrm{Rh}(+), \mathrm{Rh}(-)$ blood group distribution was $88.66 \%$ and $11.33 \%$, respectively.

When the blood groups of patients diagnosed with Covid-19 and the control group were compared, there was an increase in the number of patients with Covid-19 in blood groups A and AB, a decrease in blood group $\mathrm{O}$, and it was similar in blood group $\mathrm{B}$ and $\mathrm{Rh}$. The statistical analysis showed that there was a very significant increase in the number of individuals with blood group A in Covid-19 patients compared to healthy individuals, and almost a significant increase in the number of Covid-19 patients with blood group $\mathrm{AB}$ and a very significant decrease in the number of Covid-19 patients with blood group $\mathrm{O}$, and no significant difference in terms of $\mathrm{B}$ and $\mathrm{Rh}$ blood group system (Table 1).

\begin{tabular}{|c|c|c|c|c|}
\hline & $\begin{array}{l}\text { Covid-19 PCR }(+) \\
\mathrm{n}(\%)\end{array}$ & $\begin{array}{l}\text { Distribution of } \\
\text { blood groups in } \\
\text { Diyarbakir } \\
\text { community n (\%) }\end{array}$ & $\mathrm{X}^{2}$ & $\mathrm{p}$ \\
\hline Blood Group A & $753(45.17)$ & $50449(39.7)$ & 20.598 & 0.000 \\
\hline Blood Group B & $311(18.65)$ & $23678(18.6)$ & 0.001 & 0.979 \\
\hline Blood Group O & $447(26.81)$ & $42728(33.6)$ & 34.191 & 0.000 \\
\hline Blood Group AB & $156(9.35)$ & $10236(8.1)$ & 3.771 & 0.052 \\
\hline $\mathrm{Rh}+$ & $1478(88.66)$ & $112390(88.4)$ & 0.085 & 0.771 \\
\hline Rh- & 189 (11.33) & $14701(11.6)$ & 0.085 & 0.771 \\
\hline
\end{tabular}

Table I: Blood group distribution and analysis of Covid-19 patients and healthy individuals

Of the patients, 175 (10.5\%) were followed up in the intensive care unit and $89(50.8 \%)$ died. When the blood group distribution of the patients taken to intensive care unit was examined, A, B, O, AB blood group distribution of the patients was $42.28 \%, 21.14 \%, 26.85 \%, 9.71 \%$, and $\mathrm{Rh}(+), \mathrm{Rh}(-)$ blood group distribution was $92 \%$ and $8 \%$, respectively. And when the blood group distribution of the deceased patients was examined, A, B, O, AB blood group distribution was $40.44 \%, 22.47 \%, 26.96 \%, 10.11 \%$, and $\mathrm{Rh}(+)$, Rh (-) blood group distribution was $91.01 \%$ and $8.98 \%$, respectively. When all Covid-19 patients and those in need of intensive care and deceased ones were compared statistically, although there were percentile differences in ABO blood group distribution, this was not statistically significant (Table 2 and Table 3 ).

\begin{tabular}{lllll}
\hline & $\begin{array}{l}\text { Intensive Care n } \\
(\%)\end{array}$ & $\begin{array}{l}\text { Total Covid-19 } \\
\text { Patients n }(\%)\end{array}$ & $\mathrm{X}^{2}$ & $\mathrm{p}$ \\
\hline Blood Group A & $74(42.28)$ & $753(45.17)$ & 0.533 & 0.465 \\
Blood Group B & $37(21.14)$ & $311(18.65)$ & 0.639 & 0.424 \\
Blood Group O & $47(26.85)$ & $447(26.81)$ & 0 & 0.990 \\
Blood Group AB & $17(9.71)$ & $156(9.35)$ & 0 & 0.986 \\
Rh+ & $161(92)$ & $1478(88.66)$ & 1.475 & 0.225 \\
Rh- & $14(8)$ & $189(11.33)$ & 1.475 & 0.225 \\
\hline
\end{tabular}

Table 2: Blood group distribution and analysis of all patients diagnosed with Covid-19 and those in need of intensive care 


\begin{tabular}{lllll}
\hline & $\begin{array}{l}\text { Deceased Patients n } \\
(\%)\end{array}$ & $\begin{array}{l}\text { Total Covid-19 } \\
\text { Patients n }(\%)\end{array}$ & $\mathrm{X}^{2}$ & $\mathrm{p}$ \\
\hline Blood Group A & $36(40.44)$ & $753(45.17)$ & 0.761 & 0.383 \\
Blood Group B & $20(22.47)$ & $311(18.65)$ & 0.574 & 0.449 \\
Blood Group O & $24(26.96)$ & $447(26.81)$ & 0 & 1 \\
Blood Group AB & $9(10.11)$ & $156(9.35)$ & 0.003 & 0.959 \\
Rh+ & $81(91.01)$ & $1478(88.66)$ & 0.262 & 0.609 \\
Rh- & $8(8.98)$ & $189(11.33)$ & 0.262 & 0.609 \\
\hline
\end{tabular}

Table 3: Blood group distribution and analysis of all patients diagnosed with Covid-19 and deceased patients

\section{DISCUSSION}

A total of 1667 Covid-19 patients were included in our study. In Covid-19 patients, it was observed that the ratio of blood group $\mathrm{A}$ and $\mathrm{AB}$ was higher than in the healthy control group, and blood group $\mathrm{O}$ had a lower ratio. The statistical analysis showed that there was a very significant increase in the number of individuals with blood group A in Covid-19 patients compared to healthy individuals, almost a significant increase in the number of Covid-19 patients with blood group $\mathrm{AB}$, and a very significant decrease in the number of Covid-19 patients with blood group $\mathrm{O}(\mathrm{P}<0.001, \mathrm{P}=0,052$ and $\mathrm{P}<0.001$, respectively).

The ABO blood group system basically contains A and B antigens and their corresponding antibodies. The gene coding the antigen is located on chromosome 9q34.1-34.2. It consists of $\mathrm{A}, \mathrm{B}$ and $\mathrm{O}$ alleles, and there are 4 phenotypes (A, B, O, and $\mathrm{AB}$ blood groups). ${ }^{11,12}$ Differences in blood group antigen expression may increase or decrease host susceptibility to many infections. Blood group antigens can play a direct role in infection by serving as receptors and / or cofactors for microorganisms, parasites, and viruses. In addition, many blood group antigens facilitate intracellular uptake, signal transmission or cell adhesion through the organization of membrane microdomains. Blood group antigens may alter the natural immune response to infection. ${ }^{13}$ Since the beginning of the Covid-19 pandemic, many studies have been conducted on this subject. Zhao J YY et al. examined the ABO blood group distribution in 2,173 Covid-19 patients and showed that the frequency of blood group A was higher in Covid-19 patients than that of non-A blood groups and found that the blood group $\mathrm{O}$ was associated with a lower risk for infection compared to the non-O blood groups. ${ }^{14}$ Yuqin Wu et al. found similar results in their study on 187 Covid-19 patients and $\mathrm{H}$. Goker et al. in their study on 186 Covid-19 patients. ${ }^{15-16}$ In the study carried out by E. Arac et al., there was no significant difference between $\mathrm{ABO}$ blood groups, but strong significance was found in Rh system. ${ }^{3}$ We believe that this study had some limitations due to the fact that PCR-negative patients were also included in the study, the number of cases was small, the study was conducted at the beginning of the pandemic, and the prevalence of Covid-19 in some circles, especially among some families, rather than across community. In our study, we found that blood group A was more frequent than in community and statistically significant, blood group $\mathrm{O}$ was less frequent than in community and statistically significant, and blood group $\mathrm{AB}$ was more frequent than in community, but it was not significant. We think that blood group A is more susceptible to Covid-19 and blood group $\mathrm{O}$ is protective.

When Covid-19 patients in need of intensive care and deceased patients were compared, blood groups were shown to have no significant effects on intensive care and mortality. ABO blood groups have been associated with cardiovascular diseases before. ${ }^{17}$ It is known that thrombotic risks decrease significantly in blood group O compared to non-O blood groups ${ }^{17,18}$. Studies have shown that microthrombosis that develops in Covid-19 infection in the pulmonary vascular bed contributes significantly to acute respiratory syndrome; therefore, the use of prophylactic anticoagulants is also included in the guidelines. ${ }^{19,20}$ There are opinions arguing that the protective effect shown in blood group $\mathrm{O}$ is based on this phenomenon ${ }^{21}$. In this study, we found that blood groups were not statistically significant in predicting the patient's need for intensive care and mortality. 
In conclusion, we believe that our study is important because it is a study with the highest number of Covid19 patients diagnosed by PCR, which examined the blood group and Covid-19 relationship in our country. Our study has found that having blood group $\mathrm{O}$ may be protective, that blood group A may have greater susceptibility to the disease, but this does not affect the course of the disease and is not associated with mortality. We want to emphasize that the most important and easiest way to avoid Covid-19, regardless of the risk factor and the facilitating factor, is to maintain social distance, hand hygiene and use of masks. Although there is no significant difference between blood groups and intensive care and mortality, it can be concluded that individuals with blood group A should take stronger and stricter measures and Covid-19 patients with blood group A should be monitored more closely. Larger, multicenter and prospective studies should be conducted to determine the relationship between blood groups and Covid-19 and the protective role of blood group $\mathrm{O}$.

\section{REFERENCES}

1. AL-Khikani FH. Surveillance 2019 novel coronavirus (COVID19) spreading: Is a terrifying pandemic outbreak is soon? Biomed Biotechnol Res J 2020;4:812.

2. Fasina FO. Novel coronavirus (2019-nCoV) update: What we know and what is unknown. Asian Pacific J Tropical Med 2020;13:97.

3. E. Arac, I. Solmaz, H. Akkoc et al. Association Between the Rh Blood Group and the Covid-19 Susceptibility.UHOD, 2020; 30:081-086

4. Sayl B.S. Basic Medical Genetics,. ANKARA: Ankara University Faculty of Medicine Publications; 1982. $430 \mathrm{p}$.

5. Lindesmith L, Moe C, Marionneau S, et al. Human susceptibility and resistance to Norwalk virus infection. Nat Med. 2003;9(5):548-53.

6. Batool Z, Durrani SH, Tariq S. Association Of Abo And Rh Blood Group Types To Hepatitis B, Hepatitis C, Hiv And Syphilis Infection, A Five Year' Experience In Healthy Blood Donors In A Tertiary Care Hospital. J Ayub Med Coll Abbottabad. 2017;29(1):90-2.

7. Arac E, Solmaz I. Evaluation of blood groups in patients with anti TPO positive. Asian J Med Sci. 2019;10(6):67-70.

8. Pelzer U, Klein F, Bahra M, et al. Blood group determinates incidence for pancreatic cancer in Germany. Front Physiol . 2013;4:118. Published 2013 May 24. doi:10.3389/fphys.2013.00118

9. Cheng Y, Cheng G, Chui CH, et al. ABO blood group and susceptibility to severe acute respiratory syndrome JAMA .2005;293(12):1450-1451. doi:10.1001/jama.293.12.1450-c

10. Arac E, Solmaz I, Samanci S. ABO and Rh blood groups frequency in men, women and neonates in Diyarbakir province. Ann Med Res. 2019;26(12):2876.

11. Vasan SK, Rostgaard K, Majeed A, et al. ABO Blood Group and Risk of Thromboembolic and Arterial Disease: A Study of 1.5 Million Blood Donors. Circulation .2016;133(15):1449-1457. doi:10.1161/circulationaha.115.017563

12. Amundadottir L, Kraft P, Stolzenberg-Solomon RZ, et al. Genome-wide association study identifies variants in the ABO locus associated with susceptibility to pancreatic cancer. Nat Genet . 2009;41(9):986-990. doi:10.1038/ng.429

13. L. Cooling Blood Groups in Infection and Host Susceptibility Clin. Microbiol. Rev. 2015;2 (3):801870; doi: 10.1128/CMR.00109-14

14. Zhao J YY, Huang H, Li D, Gu D, Lu X et al. Relationship between the ABO blood group and the COVID-19 susceptibility. MedRxiv 2020. doi: 10.1101/2020.04.08.20058073

15. Wu Y, Feng Z, Li P, Yu Q. Relationship between ABO blood group distribution and clinical characteristics in patients with COVID-19. Clin Chim Acta . 2020;509:220-223. doi:10.1016/j.cca.2020.06.026

16. Göker H, Aladağ Karakulak E, Demiroğlu H, et al. The effects of blood group types on the risk of COVID-19 infection and its clinical outcome. Turk J Med Sci . 2020;50(4):679-683. doi:10.3906/sag2005-395

17. Wu O, Bayoumi N, Vickers MA, Clark $\mathrm{P} . \mathrm{ABO}(\mathrm{H})$ blood groups and vascular disease: a systematic review and metaanalysis. Journal of Thrombosis and Haemostasis 2008;6(1): 62-69. doi: 10.1111/j.1538- 
7836.2007.02818.x

18. Jenkins PV, O'Donnell JS. ABO blood group determines plasma von Willebrand factor levels: a biologic function after all? Transfusion 2006;46(10):1836-1844. doi: 10.1111/j.1537- 2995.2006.00975.x

19. Tang N, Li D, Wang X, Sun Z. Abnormal coagulation parameters are associated with poor prognosis in patients with novel coronavirus pneumonia. Journal of Thrombosis and Haemostasis 2020;18(4): 844-847. doi: $10.1111 /$ jth. 14768

20. O'donnell J, Sharif K, Emery P, Bridgewood C, Mcgonagle D. Immune mechanisms of pulmonary intravascular coagulopathy in COVID-19 pneumonia. Lancet Rheumatology 2020 May 07 [online ahead of print]. doi: 10.13140/RG.2.2.19782.83521

21. O'Sullivan JM, Ward S, Fogarty H, O'Donnell JS. More on "association between ABO blood groups and risk of SARSCoV-2 pneumonia". British Journal of Haematology 2020 May 18 [online ahead of print]. doi: $10.1111 /$ bjh. 16845 